\title{
TRÊS PONTOS DE VISTA SOBRE O CAPITALISMO ATUAL: UM ESTUDO A PARTIR DE HARVEY, JAMESON, ZIZEK, DELEUZE E NEGRI
}

\author{
TRES PUNTOS DE VISTA SOBRE EL CAPITALISMO ACTUAL: UN ESTUDIO \\ DESDE HARVEY, JAMESON, ŽIŽEK, DELEUZE Y NEGRI \\ THREE POINTS OF VIEW ABOUT TODAY'S CAPITALISM: A STUDY BASED \\ ON HARVEY, JAMESON, ZIZEK, DELEUZE AND NEGRI \\ Pedro Sobrino Laureano \\ Universidade Federal de São João del Rei, São João del Rei/MG, Brasil
}

Carlos Augusto Peixoto Junior

Pontifícia Universidade Católica do Rio de Janeiro, Rio de Janeiro/RJ, Brasil

\begin{abstract}
RESUMO
Procuramos apresentar e relacionar três visões distintas sobre o capitalismo. A primeira, compartilhada por Deleuze, Guattari, Negri e Hardt, aposta na radicalização da diferença contra os mecanismos modulatórios do mercado mundial. A segunda, presente nas teorias de Jameson e Harvey, critica o repudio pós-moderno às categorias universalistas, caracterizando o culto contemporâneo ao hibridismo e à pluralidade como reforço ideológico do novo capitalismo flexível surgido nos anos 70. Finalmente, no pensamento de Zizek, a crítica à ideologia da subjetividade múltipla é articulada à denegação capitalista da dimensão negativa, ou traumática, do sujeito. Buscamos sustentar por que as análises de Deleuze, Guattari, Negri e Hardt nos parecem mais pertinentes, ao procurarem positivar os elementos de constituição e resistência já presentes na atual conjuntura.
\end{abstract}

Palavras-chave: capitalismo; subjetividade; diferença; pós-modernidade.

\section{RESUMEN}

Buscamos introducir y conectar tres distintos puntos de vista sobre el capitalismo. El primero, compartido por Deleuze, Guattari, Negri y Hardt, apuesta en la radicalización de la diferencia frente a los mecanismos moduladores del mercado mundial. El segundo, presente en las teorías de Jameson y Harvey, critica la aversión postmodernista a las categorías universalistas, convertiendo-se en el culto contemporáneo a la hibridez y a la pluralidad como refuerzo ideológico del nuevo capitalismo flexible que apareció en los años 70 . Finalmente, en el pensamiento de Zizek, la crítica de la ideología de la múltiple subjetividad se articula a la denegación capitalista de la dimensión negativa, o traumática, del sujeto. Buscamos mostrar porque el análisis de Deleuze, Guattari, Negri y Hardt parecen más relevantes, registrando a los elementos positivos de la Constitución y fuerza ya presente en la actual coyuntura.

Palabras clave: capitalismo; subjetividad; diferencia; posmodernidad.

\begin{abstract}
We seek to expose three different visions concerning to the capitalist system. The first, which can be found in the works of Deleuze, Guattari, Negri and Hardt, sustains the radicalization of difference against the modulatory mechanisms of the global market. The second, present in the theories of Frederic Jameson and David Harvey, criticizes post modern's interdiction of universal categories, presenting the contemporary cult of difference and flexibility as the ideological reflection of the new flexible capitalism emerged in the seventies. Finally, in the thought of Slavoj Zizek, the criticism of the multiple subjectivity ideology is articulated with capitalism denegation of the negative, or traumatic, aspect of the subject. We search to sustain why the analyses of Deleuze, Guattari, Negri and Hardt appears to us to be more significant, since these authors search to apprehend, in a positive way, the movements of resistance and constitution that are present on today's conjuncture.
\end{abstract}

Keywords: capitalism; subjectivity; difference; postmodernity. 
Partimos da ideia de que nas obras de Deleuze e Guattari encontramos uma teoria original do capitalismo que, ao cruzar o pensamento de Freud com o de Marx, não produz uma síntese freudomarxista, mas, por meio de um processo preciso de seleção imposto a estes autores, produz uma nova caracterização do sistema que é de fundamental importância para o pensamento contemporâneo. O que emerge da teoria sobre o capitalismo construída em O anti-Édipo (1972/2010) e Mil Platôs (1980/1997b) é uma apreciação do sistema baseada na relação indissociável entre economia e desejo, instintos e instituições, tendo como único critério a relação do capital com a diferença, pensada radicalmente. As categorias do social e do individual, do sociológico e do psicológico são anuladas em nome de um terceiro não dialético: a diferença nela mesma, fora de sua modulação pelo discurso multiculturalista de tolerância, ou neoliberal de hibridismo mercadológico.

Em seguida, procuraremos apresentar as reflexões sobre o capitalismo contemporâneo e a pós-modernidade presentes nas obras de Fredric Jameson e David Harvey. A pós-modernidade é caracterizada por estes autores como ideologia do novo capitalismo flexível surgido nos anos 70. Desde então, o que se impõe ao debate é a questão do pluralismo, da diferença e do hibridismo. Harvey e Jameson, ao não compartilharem do entusiasmo com a nova subjetividade que emerge na pós-modernidade, propõem uma questão importante para o pensamento contemporâneo: num mundo unificado pelo mercado, apostar no caráter plural da subjetividade constitui alternativa eficaz de resistência política?

Nas teses de Slavoj Zizek também nos confrontaremos com outro diagnóstico das relações entre subjetividade e capitalismo. As análises de Zizek, distintas em pontos essenciais daquelas realizadas por Deleuze e Guattari, apresentam elementos importantes de convergência com as de Jameson e Harvey. O autor acusa o conformismo presente nos discursos que celebram a diferença e o múltiplo, apontando que a nova subjetividade estimada pela ideologia do capitalismo flexível ajusta-se perfeitamente às exigências do mercado. Para Zizek, foi pela afirmação irrestrita do particularismo que o capital pôde universalizar-se como horizonte político único.

Por fim, procuraremos defender por que, em nossa visão, as ideias de Deleuze e Guattari acerca da relação entre capitalismo e desejo permanecem imprescindíveis para o debate contemporâneo, mesmo em face da capacidade de reintegração, pelo mercado, dos esforços de autores e movimentos políticos que se pretendem críticos do capital ${ }^{1}$. Para tal, também nos serviremos de algumas das teses de Antonio Negri e Michael Hardt que, insistindo no elemento de radicalidade da singularidade e da diferença, contribuem com ferramentas conceituais preciosas para pensarmos formas contemporâneas de resistência.

\section{Deleuze, Guattari e o capital}

Uma teoria política do capitalismo começa a ser construída por Deleuze e Guattari em $O$ anti-Édipo (1972/2010), mais marcadamente no terceiro capítulo do livro, intitulado "Selvagens, bárbaros e civilizados". Segundo Sibertin-Blanc (2010), esta teoria possui uma intenção declarada: medir as formações sociais a partir da desmedida da diferença tolerada e/ou permitida por uma determinada "duração histórica". A classificação não se insere numa categorização estanque e, de fato, Mil Platôs (1980/1997b) irá radicalizar a descrição ainda evolutiva de $O$ anti-Édipo, ao multiplicar o que os autores denominam agenciamentos coletivos do desejo: sistemas de relações mais ou menos estáveis que efetuam, estabilizam, regimes de potência ${ }^{2}$. Temos, então, agenciamentos selvagens, bárbaros (estatistas) e civilizados (capitalistas), por certo; mas, também migrantes, nômades, sociedades ecumênicas, bandos... (Deleuze \& Guattari, 1980/1997b)

De fato, a grande oposição que perpassa o segundo tomo de Capitalismo e esquizofrenia será aquela entre os nômades e os Estados. Mas, com isto, o capitalismo não desaparece das análises. Pelo contrário, ele é apontado como sistema que se caracteriza pelo notável potencial de mistura, se inserindo como um vírus nas mais diversas formações sociais - nos poros dos Estados e Impérios, atravessando continentes, unindo pontos separados no tempo e no espaço. Potência do capital para o hibridismo; ainda tímida, entretanto, quando comparada a uma potência nômade. Mas certamente mais vasta do que aquela dos aparelhos de captura estatais, procedendo pela segmentação e sobrecodificação dos fluxos sociais.

Surge uma primeira premissa: "não há capitalismo universal" 3; justamente porque o capitalismo deve operar sobre a diferença - é um sistema de integração perpétua, e não de exclusão absoluta. Como exemplo podemos apontar a versão deleuze-guattariana da acumulação primitiva, no século XVII europeu: os fluxos de capital-dinheiro, dado seu potencial de desterritorialização superior, subordinam os estados absolutistas. Desterritorialização e potência conjugamse na subordinação dos estados a peças (mesmo que essenciais) na maquinaria do capital. A partir desse momento, então, caberá "à desterritorialização de Estado moderar a desterritorialização superior 
do capital e oferecer a este reterritorialidades compensatórias" (Deleuze \& Guattari, 1980/1997b, p.154). A acumulação primitiva não é, portanto, um mito de origem, mas a descrição de uma mutação na tecnologia do poder, próxima àquilo que Foucault (1975) descreve, ao teorizar sobre os novos mecanismos de poder que, na modernidade europeia, fazem emergir a sociedade disciplinar.

Mercados sempre existiram nos poros de outras formações sociais: regulados pelos Impérios, conjurados pelos agenciamentos tribais. O espantoso, para os autores, é que, em dado momento na história, no continente europeu, aquilo que era temido e execrado por outras formações sociais - a desterritorializado e descodificação dos fluxos de desejo - possa fazer sistema. Fenômeno espantoso, dependente de uma série de contingências históricas - fluxos de capitaldinheiro libertos das regulações estatais, subordinando os Estados; fluxos de trabalhadores "livres", desapropriados das terras, possuindo apenas a força de trabalho para a venda.

Ora, deste momento de irrupção da diferença - momento singular em que a história se abre à virtualidade do desconhecido e do imprevisível efetua-se uma nova máquina social, por meio do encontro desses dois fluxos, ou seja, pela subordinação dos trabalhadores ao capital. E esta nova máquina é, constitutivamente, contraditória. Ao impor sua regularidade ao socius, ela inclui, em seus próprios cálculos, a abertura para a diferença, para os fluxos do desejo. Mas, se os inclui, é apenas para, em seguida, domesticá-los, reenviando a produção dos fluxos desejantes às formas tradicionais da representação e da soberania. De fato, no capitalismo "o campo social não remete mais, como nos Impérios, a um limite exterior que o limita de cima, mas a limites interiores imanentes, que não cessam de se deslocar, alargando o sistema, e que se constituem deslocando-se" (Deleuze \& Guattari, 1991, p.127).

Algo do acontecimento (desterritorialização e descodificação) foi traído, pela sistematização do capitalismo como prática social hegemônica. $\mathrm{O}$ sistema recua, aterrorizado, ante a potência que ele mesmo libera e da qual depende, impondo limites interiores aos fluxos do desejo. Porém, na insistência da diferença, repete-se a cada momento a possibilidade de "resolver" a contradição capitalista (liberação e apropriação dos fluxos desejantes) fora da sintomática solução de compromisso que o capital impõe. Desterritorialização e descodificação absolutas: maio de 68, revoltas árabes de 2011, etc.

Antes de prosseguirmos nossa análise devemos, entretanto, recuar um pouco e nos perguntar: o que é um fluxo? Esta categoria analítica mínima será abandona em Mil Platôs, porém apenas nominalmente: fluxo, sendo o que escapa à codificação e à representação, possui a mesma definição real que em Mil Platôs é reservada aos conceitos de devir, multiplicidade, rizoma e nomadismo. Ou seja, trata-se de sistemas a-centrados, não arborescentes: rizomas (Deleuze \& Guattari, 1980/1995); de conjuntos abertos de pontos singulares não subsumíveis a uma unidade real ou virtual: multiplicidades (Deleuze \& Guattari, 1980/1995); de passagens que subvertem os termos de partida, afirmando uma dupla diferença aonde o ponto de origem é abolido: devires (Deleuze \& Guattari, 1980/1997a); e, finalmente, de formações sociais não estabilizadas nos espaços sedentários dos Impérios, ocupando de maneira intensiva o espaço e o tempo: nomadismo (Deleuze \& Guattari, 1980/1997b). Enfim, falamos aqui de algo que constitui matéria preciosa para o capitalismo: a produção desejante, que atravessa a subjetividade para além das categorias do coletivo ou do individual, do psicológico ou do sociológico, abrindo caminho para a criação.

É necessário, então, desvincular a categoria de desejo daquela conceituada na psicanalise freudiana e lacaniana; ele não é a propriedade de um indivíduo barrado em seu acesso ao absoluto. Não se constitui através de uma falta inscrita no individuo ou no social (o Outro barrado lacaniano). Ele escorre entre os indivíduos efetuados, entre as formações sociais, confrontando-os com a radicalidade da dessemelhança e da diferença. Um meio de pura exterioridade que não reconhece formas instituídas. Ora, o mesmo se passa com o capital: vimos que, se não há capitalismo universal, é justamente pela potência desterritorializante que tem o sistema de misturar-se a formações sociais heterogêneas. Fenômeno patente nas misturas atuais do capital nas sociedades chinesa, japonesa, asiáticas, indígenas, etc., constituindo aquilo que se chama globalização, ou Capitalismo Mundial Integrado (CMI), conforme afirma Guattari (2005). Se o capital opera diretamente sobre o campo de imanência do desejo, como elaborar uma política "anti", ou "pós"-capitalista?

Justamente, o capitalismo impõe um duplo impasse ao desejo; é um agenciamento social que funciona através de dois imperativos contraditórios: que o desejo produza, mas que sua produção seja reapropriada pelos mecanismos da exclusão material e subjetiva, que Deleuze e Guattari denominam axiomáticos, acumulação infinita de capital pelo homem privado. O indivíduo privado do humanismo burguês, nascido da "privatização generalizada dos órgãos" (Deleuze \& Guattari, 2010), é o centro do movimento 
regressivo de recodificação e reterritorialização dos fluxos do desejo. Ao trabalhador, impõe-se o trabalho infinito; ao capitalista, a acumulação infinita. Internalização da dívida infinita, que antes se encontrava objetivada na instância transcendente dos Estados e Impérios. A axiomática do homem privado exprime a "independência de um Sujeito que constitui agora o único laço" (Deleuze \& Guattari, 1980/1997b, p.151). O laço de dominação, antes realizado em nome de uma sobrecodificação transcendente que estriava o espaço segundo um centro emanativo, agora se torna pessoal, interior a um Sujeito abstrato e privado.

As apostas de Deleuze e Guattari para uma sociedade "pós-capitalista" encontram-se, portanto, na radicalização da potência da diferença, do hibridismo e na nomadização da subjetividade. Subverter as dicotomias entre o social-estatal da sobrecodificação e o individual-privado do mercado para adentrar na dimensão não psicológica da criação. $\mathrm{O}$ meio de interioridade acionado pelo capital coloca a subjetividade num duplo impasse. Por um lado, seguir as linhas de desterritorialização, que são permitidas pela face expansiva do sistema, em seu "momento" revolucionário; por outro, agarrar-se às, "neo-territorialidades ... artificiais, residuais, arcaicas" (Deleuze \& Guattari, 2010, p. 341), que ressuscitam codificações e sobrecodificações, fazendo retornar as superstições, tais como as do indivíduo privado, da família nuclear, das nacionalidades, racismos, etc. Para a subjetividade, presa entre duas alternativas mutuamente exclusivas, o duplo impasse capitalista é o único responsável pela esquizofrenização do campo social e pela falência do laço social; não - como parecem querer alguns autores - a ausência de leis, ou limites.

A saída revolucionária não repousa em nenhuma contradição entre classes, em nenhuma liberação do "homem", mas na possibilidade de se subverter as classes sociais e fugir aos mecanismos representativos da nacionalidade, identidade, família, etc. Mecanismos que, como fantasmas, retornam para assombrar o campo social com superstições, manias, arcaísmos, quando os fluxos desejantes pareciam apontar para a formação de uma nova terra, excessiva, monstruosa, descomunal.

\section{Pós-modernidade e capitalismo flexível}

Como relacionar esta descrição do capitalismo, formulada em $O$ anti-Édipo e Mil Platôs, com as mutações do capitalismo encontradas a partir dos anos 70? Primeiramente, tratemos de definir melhor essas mutações, especificando por que elas trazem novos problemas ao pensamento contemporâneo; não apenas à filosofia da diferença deleuze-guattariana, mas também a todo pensamento crítico que queira compreender a conjuntura atual, apontando saídas para as formas inéditas de dominação que se cristalizam ante nossos olhos. Para realizar tal empreendimento, buscaremos as análises de Fredric Jameson e David Harvey sobre a passagem da modernidade à pósmodernidade e a relação do capitalismo tardio com a nova subjetividade, híbrida e flexível. Em seguida, apresentaremos o diagnóstico do capitalismo contemporâneo feito por Slavoj Zizek, tendo como base a teoria lacaniana.

Para Jameson e Harvey, a exaltação pósmoderna da diferença, da fragmentação e do localismo é um fenômeno que só pode ser compreendido através das transformações infraestruturais do capital: "a ascensão do pós-modernismo ... reflete uma mudança na maneira de operação do capitalismo em nossos dias" (Harvey, 1989, p. 107). Os autores enxergam, na transição do modelo fordista-keynesiano do pós-guerra à acumulação flexível, a partir do começo dos anos 70 , uma nova fase, inédita em extensão e intensidade, no desenvolvimento do modo capitalista de produção.

No fordismo-keynesianismo, a busca por lucros encontrava-se limitada pela pressão dos sindicatos e pela regulamentação do Estado do bem-estar social. Já na acumulação flexível, as reivindicações trabalhistas são abafadas pela flexibilização e precarização do trabalho, e os Estados, privados de sua força regulamentadora e previdenciária, inclinamse à política neoliberal, comprometida em criar um "clima favorável aos negócios, e, portanto, otimizar as condições para a acumulação capitalista, não importando as consequências para o emprego e o bemestar social" (Harvey, 2006, p.25).

Ou seja, a pós-modernidade não aponta apenas para a liberação das diferenças de gênero, sexo e cultura, abafadas pelos modelos totalitários da modernidade; ela é sintoma da universalização contemporânea do capitalismo que, após a queda do muro de Berlim, busca excluir todas as alternativas contrárias à lógica da acumulação privada. O capitalismo flexível, ou tardio, torna-se capaz de endogeneizar as reinvindicações feitas nos anos 60 pela afirmação da alteridade, da diferença e da criatividade, pela liberação sexual, de gênero e racial, dentro de um novo dogma universalista hiperabrangente. Todas as diferenças (de gênero, sexo, etnia, cultura, etc.) são, ao menos tendencialmente, abolidas quando reintegradas pela modulação única do valor econômico. Trata-se da emergência do capitalismo neoliberal que, dando marcha a um novo ciclo de acumulação, presa a flexibilidade, a dispersão 
e a fragmentação, tanto na esfera produtiva quanto na subjetiva. Neste sentido, é o individualismo, e não a diferença, que constitui a tônica de um mundo que já não aposta na política ligada à esfera pública ou estatal como motor de transformação e justiça social.

As mudanças ideológicas que podem ser observadas a partir do fim dos anos 60 até os dias de hoje devem, então, ser elucidadas do ponto de vista das transformações econômicas. O ocaso do período fordista-keynesianista de acumulação e a emergência do novo paradigma constituem, para estes autores, uma necessidade interna ao capital, e não uma reação às lutas e revoltas dos anos 60. Estas lutas, ao concentraremse sobre a possibilidade de diferenciação, respeito à diversidade e à heterogeneidade, propiciaram um terreno livre de resistências à subsequente dominação irrestrita do mercado.

A ideologia pós-moderna, presente nos discursos filosóficos, mercadológicos (marketing, publicidade, neomanagement), midiáticos e culturais, ao celebrar as diferenças, paradoxalmente, confirmaria a inédita universalização do capital: "A padronização projetada pela globalização capitalista, neste ... mais recente estágio do sistema, lança uma dúvida considerável sobre todas essas piedosas esperanças por uma variedade cultural, num mundo ... colonizado por uma ordem universal do mercado" (Jameson, 2003, p.22).

A globalização capitalista põe a superestrutura ideológica para trabalhar. Ao invés de apenas legitimar e ocultar a exploração social realizada ao nível da produção econômica, a superestrutura fornece as diretrizes - os sistemas simbólicos e desejantes - que deverão ser seguidas pela dinâmica do mercado. Este fenômeno aponta para a inédita universalização do capital: "O pós-modernismo é o que se obtêm quando o processo de modernização e a natureza desaparecem para sempre" (Jameson, 1997, p. 102). Ou seja, quando o mundo se encontra de tal forma unificado pelo sistema que as últimas fronteiras à mercadificação geral da vida, como o inconsciente, a natureza e a sexualidade, parecem ter sido franqueadas.

O que caracteriza o mundo contemporâneo, nesta perspectiva, é a presença de dois imperativos sociais contraditórios. Por um lado, a tela fantasmática da consciência imediata grita: "Seja diferente, híbrido, flexível"! Por outro, o real da produção econômica, devidamente recalcado pelas representações ideológicas, impõe uma universalização em que a lógica de mercado se afirma como único paradigma social possível. Qualquer pensamento que busque representar o todo da produção econômica e articulálo numa narrativa crítica é recalcado, condenado como totalitário ou dogmático.
O efeito desta conjuntura é a esquizofrenização do laço social, já que o universal do mercado, operando através da fragmentação e da dispersão celebradas pela ideologia, frustra qualquer tipo de sentido coletivo, de laço social estável que poderia fazer frente à globalização capitalista. A subjetividade contemporânea caracteriza-se, então, por "um amontoado de significantes distintos e não relacionados; ... a experiência dos puros significantes materiais ... uma série de puros presentes, não relacionados no tempo" (Jameson, 1997, p.53). O puro jogo das diferenças entra em contradição com a unificação realizada pelo mercado global, ao mesmo tempo em que, no nível ideológico, serve para intensificá-la e mascará-la. O repúdio a pensar a totalização permite a abertura completa da subjetividade para a mercantilização generalizada. O psicológico e o individual encobrem o social, o coletivo.

A subjetividade pós-moderna não pode ser múltipla porque é capitalista. A unificação realizada pelo mercado surge como ponto cego das análises pósmodernas, ponto recalcado, relegando este discurso à posição de apanágio ideológico da nova subjetividade de que o mercado necessita para intensificar sua dominação. Trata-se da incapacidade de se pensar a totalidade do sistema, de se elevar da particularidade celebrada pelo pós-modernismo ao nível abstrato e universal, único ponto de onde se poderia elaborar um pensamento crítico contra a subsunção da sociedade pela ordem capitalista.

As mutações na infraestrutura produtiva, tais como a precarização dos contratos laborais, o ocaso da força sindical, a flexibilização da produção e do consumo e o desmonte do Estado do bem-estar social, são reforçadas pelas mutações ideológicas das subjetividades. Estas, no momento em que pretendem ter ultrapassado a identidade fixa do individualismo burguês, tornam-se, contraditoriamente, hipernarcísicas, alienadas de sua participação em qualquer coletividade. Subjetividades que acabam, portanto, intensificando a lógica do capitalismo, já que esta é, segundo Jameson, "dispersiva e atomística, individualística, uma antisociedade mais do que uma sociedade" (Jameson, 1991, p.112).

Devemos ressaltar que Jameson e Harvey, certamente, não são desfavoráveis à afirmação das diferenças, contra os padrões majoritários. Os autores apenas apontam que o discurso em torno da diferença deve ser articulado a uma nova concepção de coletividade que possa fazer face ao poder, ao mesmo tempo inclusivo e segregacionista, do capitalismo flexível. O mercado é capaz de acolher e mesmo demandar! - as diferenças pós-modernas; o 
que precisamos, para estes autores, é de uma crítica que seja capaz de articular essas novas subjetividades fragmentárias numa concepção não normativa de coletividade.

\section{Zizek e a denegação capitalista do trauma}

As análises de Slavoj Zizek, inspiradas na obra lacaniana e numa leitura original do pensamento hegeliano, parecem convergir em alguns aspectos essenciais com as de Fredric Jameson e David Harvey. $\mathrm{O}$ autor concorda que a patente contradição entre o discurso pós-moderno, liberal e multiculturalista, de um lado, e as práticas unificantes e globalizantes do mercado, por outro, revelam que a retórica da diferença nada mais é do que a nova forma da ideologia, no mundo contemporâneo.

Zizek baseia sua análise do capitalismo no pensamento lacaniano do Real ${ }^{4}$. Como núcleo traumático irrepresentável pela linguagem, o Real é o excesso que escapa, ao mesmo tempo em que é produzido pela ordem do discurso. $\mathrm{O}$ autor enfatiza que o novo capitalismo, ao celebrar o caráter múltiplo da subjetividade, oculta esta dimensão fendida, ou traumática, do sujeito. Ao denegar sua relação com o Real, a subjetividade aliena-se daquilo que é, entretanto, condição de seu desejo.

O recalque contemporâneo do problema da totalidade não nos faz escapar aos discursos universalistas associados à modernidade - emancipação do homem, do proletariado, do Estado Universal, etc. Ao lado da afirmação híbrida e positiva de uma miríade de identidades flutuantes, o que temos, por meio da imposição da ordem unificante do mercado, é o retorno deste universal recalcado. Entre os dois imperativos - o do mercado e o da subjetividade diferencial - o que se encontra esquecido é, mais profundamente, o núcleo irredutível de negatividade associado ao trauma e ao Real.

Para Zizek, a pós-modernidade acredita numa subjetividade fundamentalmente positiva, em que múltiplas determinações convivem sem hierarquia, sem necessidade de englobamento unificante de um termo totalizador. Mas, pretendendo fugir do universalismo associado ao pensamento moderno, o que é recusada é a própria presença de uma ausência constitutiva na ordem do ser; ausência cuja insistência fundamental caracteriza o homem como ser social.

O superego pós-moderno, caracterizado por Zizek como a nova matriz ideológica dominante nas sociedades pós-industriais, torna-se, então, agente de uma injunção ao gozo. É, contraditoriamente, um significante-mestre que nega cinicamente seu papel de hegemonia, pois faz acreditar, ideologicamente, que a dissimetria entre o particular e o universal, entre o indivíduo e a sociedade, mais que poder ser resolvida, não existe: "O que temos é uma proibição completa de qualquer tipo particular de identificação, o que significa que o Outro deve ser entendido como uma abstração, como se já estivesse morto" (Zizek, 2006, p.146).

O particular não necessita mais identificar-se perante um Outro que sanciona (limita) sua posição subjetiva. Se o Outro, na ideologia capitalista, não existe, tudo se torna aparentemente permitido. $\mathrm{O}$ gozo do particular - a ação livre do indivíduo em detrimento de qualquer ordenamento moral universal - vincula a ilusão de que não há contradição entre interesse privado e interesse geral, ilusão ideológica respaldada por outros significantes-mestres do mundo atual, como "livre-concorrência", "democracia", "igualdade", "direitos humanos", etc. (Zizek, 2006, p. 27).

Mas, para Zizek, o declínio da lei paterna, como ocaso de um significante mestre, deve ser questionado, pois significa apenas o ocultamento ideológico da função repressora e englobante do capitalismo atual. $\mathrm{O}$ capitalismo, como sistema imanente, ou seja, que não recorre a nenhum universal transcendente que venha ordenar as relações sociais, procura tamponar o núcleo traumático do sujeito, dissolvendo a dicotomia entre o particular e o universal através da multiplicação infinita dos particulares. É neste sentido que Zizek lê a multiplicação das modernidades, ou seja, a ideologia da hibridização e da multiplicidade, característica da pós-modernidade:

na medida em que, de acordo com Freud, o ato de desmentir a castração é apresentado como a multiplicação dos representantes-do-falo (uma miríade de falos assina a castração, a falta do próprio), é fácil conceber essa multiplicidade de modernidades como uma forma de desmentido própria ao fetiche. (Zizek, 2008, p.54)

Para o filósofo, o capital, como forma estruturante das relações sociais, ainda é o universal englobante ${ }^{5}$, mas, ao contrário da figura tradicional que confere ao universal o papel de agente da lei e da castração, é um universal que nega seu papel castrador, pois nega a própria presença da castração. Nega a própria ausência constitutiva, o núcleo traumático que define o ser do homem, já que "para criar um sistema global universal, as forças do capitalismo procuram esconder a violência político-discursiva de sua construção" (Zizek, 2006, p. 25).

Por isso, a injunção ao gozo em detrimento de qualquer lei, característica do superego pós-moderno, 
vem alimentar o fetiche que constitui o individualismo contemporâneo. Coloca-o numa ordem irrealizável de satisfação narcísica que, longe de significar a ausência de proibição ou de culpa, o intensifica, pois proíbe exatamente aquilo que no sujeito constitui seu gesto fundamental: o negativo. Segundo Zizek, este fenômeno constitui

o paradoxo necessariamente inverso pelo qual o prazer, numa sociedade supostamente permissiva, se transforma em dever. Os sujeitos se sentem na obrigação de se divertir, de "curtir a vida", como se isso fosse uma espécie de dever, e, consequentemente, se sentem culpados quando não são felizes. (Zizek, 1999, p. 7)

O verdadeiro escândalo, para o filósofo esloveno, não é que se possa gozar livremente, ou que se possa assumir papéis diversos na miríade de identidades hibridas da pós-modernidade, mas que se possa afirmar a falha constitutiva, o trauma original, dissimetria radical que dá vazão à atividade verdadeiramente criadora do homem - sua atividade revolucionária que, através do contato com o núcleo irredutível de violência do trauma, torna possível o impossível (Zizek, 2006, p.201). Este tornar possível o impossível aparece, portanto, como uma nova forma de relação social, forma verdadeiramente anticapitalista. Nesta forma, o núcleo traumático não é, por um lado, negado pela hegemonia de um universal transcendente que oprime os particulares, nem, por outro, denegado pela multiplicação dos indivíduos e de suas diferenças. A falha constitutiva do desejo humano é afirmada por meio da desestabilização de qualquer adequação entre universal e particular: a tragédia do trauma, sendo afirmada, torna-se núcleo de ação política transformadora.

O que é aterrador não é que o Real - como instância liberta de todas as constrições da ordem seja impossível, mas que, como impossível, ele seja possível; é a realidade de um encontro traumático que desestabiliza a ordem do ser, ao qual não podemos nos furtar. É um núcleo de negatividade, inscrito na ordem simbólica, que condiciona esta ordem, e que insiste em assediá-la. Furtar-se ao encontro traumático é o que caracteriza o capitalismo em sua dinâmica pseudo-libertária, prometendo, conforme os exemplos de Zizek: café sem açúcar, cerveja sem álcool, comida sem gordura - ou seja, uma assepsia impossível na constituição do subjetivo. E, destes exemplos prosaicos, Zizek passa para o exemplo da revolução sem violência, ou seja, de uma promessa de transformação social que não passe por um encontro traumático, que não seja confrontada com este núcleo de negatividade.

\section{A aposta na radicalização da diferença}

Dentre as questões que apresentamos a respeito do capitalismo contemporâneo, podemos constatar que a posição de Deleuze e Guattari apresenta diferenças significativas em relação às de Jameson, Harvey e Zizek. Primeiramente, nas considerações deleuzeguattarianas, o capitalismo não é apresentado como sistema universalizante, ao contrário do que acontece nas obras dos outros autores trabalhados. Disto deriva uma primeira consequência: as diferenças que integram a máquina capitalista pós-moderna não são nunca, para Deleuze e Guattari, absorvidas pelo sistema. Há um limite para a tolerância do capitalismo à diferença; seu ato de domá-la é sempre parcial, ambíguo. Uma parte resta não assinalável, em estado, digamos, selvagem, pronta a voltar-se contra as modulações "híbridas" do mercado. A diferença recalcada retorna, seja como uma inadaptabilidade objetiva e/ou subjetiva aos dogmas econômicos, seja como positivação transformadora da potência de diferenciação fora e contra as estruturas mercadológicas.

Se essas diferenças radicais mesclam-se, inevitavelmente, com aqueles que são axiomatizadas pelo sistema, não será absorvendo-as numa nova coletividade representativa, ou confrontando-as com o negativo que poderemos desafiar a lógica do mercado. Pelo contrário, somente levando o movimento de dispersão, de hibridização e diferenciação até o fim é que poder-se-á atravessar o muro da modulação capitalista.

Gostaríamos de ressaltar um segundo aspecto de distinção importante. Para Deleuze e Guattari, a esquizofrenização do campo social é pensada por meio da recodificação e reterritorialização capitalista do desejo. Este movimento não pode ser relacionado, como para Jameson e Harvey, à emergência do culto à diferença, do hibridismo e do pluralismo. Pelo contrário, é a parada no movimento de radicalização da diferença que, reintegrando-a nas estruturas do mercado, acarreta na fragmentação caótica do campo social. Neste sentido, não caberia, para os autores, clamar pela emergência de novas formas de coletividade e de representação do todo pela elaboração de "mapas cognitivos" (Jameson, 1997, p.77), conforme a proposta apontada por Jameson. Simplesmente, não há oposição ontológica entre o particular e o coletivo, o psicológico e o social; estas divisões, certamente presentes no mundo contemporâneo, são objetivações do poder, decorrências de sua eficácia. A afirmação da diferença e da singularidade é a possibilidade de construção de novas formas de sociabilidade fora das dicotomias entre a parte e o todo, o indivíduo e a sociedade, o público e o privado. 
A captura, pelo discurso pós-moderno e pela lógica do capitalismo flexível, das noções de hibridismo e pluralidade, não significa que o pensamento crítico deva renunciar a estas categorias ${ }^{6}$. O movimento de afirmação da diferença deve ser, ao contrário, levado à sua radicalidade instituinte, insurgindo-se contra as modulações mercadológicas por meio da construção positiva de alternativas institucionais e subjetivas. No pensamento de Jameson, Zizek e Harvey, ainda influenciados por uma concepção dialética das relações entre poder e desejo, corremos o risco de, ao criticar os aparelhos reais de opressão presentes no mundo contemporâneo, jogarmos fora as conquistas (reais!) obtidas pelas lutas que se acumulam ao longo da história, e que, marcadamente nos anos 60 , estiveram associadas à afirmação da diferença contra os padrões majoritários, os discursos universais e as hierarquias institucionais.

A ideia zizekiana da denegação do trauma e da negatividade pelas sociedades contemporâneas corre o risco de, prezando o negativo como dimensão necessária pela qual o desejo deve ser mediado para revolucionar as estruturas sociais, ignorar os avanços reais, os ganhos efetivos que, mesmo ao lado das atrocidades cotidianas vinculadas à "socialização de mercado", encontram-se presentes no mundo contemporâneo. Podemos depreender das obras de Deleuze e Guattari que, pelo contrário, somente pela radicalização dos movimentos constituintes que se encontram imediatamente presentes no mundo atual poderemos confrontar as instituições do mercado.

Para finalizar, gostaríamos de apontar brevemente como, na obra de Antonio Negri e Michael Hardt, também encontramos elementos importantes para defendermos a valorização da afirmação da diferença em detrimento da modulação mercadológica contemporânea. De fato, os autores, retomando o cerne das concepções deleuze-guattarianas sobre a relação entre capitalismo, desejo e revolução, afirmam que devemos separar radicalmente poder constituinte e constituído, Império e Multidão, trabalho morto e trabalho vivo. Essa separação, no entanto, não nos relança numa concepção dicotômica simplista, mas permite isolar, dentro do capitalismo atual, um núcleo positivo que, mesmo instrumentalizado, domesticado e controlado pelo sistema, permanece como base ontológica sem a qual a relação de capital simplesmente não existiria. Segundo os autores,

O capital precisa do trabalho assim como o trabalho precisa do capital. Marx identificou aqui uma contradição fundamental. O trabalho é antagônico ao capital e representa constantemente uma ameaça a produção, através das greves, da sabotagem, e de outros subterfúgios, mas o capital não pode dispensar o trabalho. É obrigado a coabitar intimamente com o inimigo. Em outras palavras, o capital deve explorar a força de trabalho dos trabalhadores, mas não pode realmente oprimi-los, reprimi-los ou excluí-los. Nada pode sem sua produtividade. (Negri \& Hardt, 2004, p.417)

Ou seja, o que é afirmado aqui, claramente, é que o poder não produz. Se associarmos a proliferação de diferenças "pós-modernas" somente à necessidade do mando capitalista de integrar contingentes cada vez maiores de trabalhadores em estruturas cada vez mais precárias de emprego (e desemprego); se fizermos equivaler a emergência das subjetividades híbridas à necessidade, para o capital, de criar novos bens de consumo, novas "modas" ou mercados ligados ao individualismo e ao "psicologismo", alienados de qualquer sentido comunitário ou societário, recaímos na concepção que entrega ao capitalismo a capacidade de hibridização, diferenciação, desestabilização de hierarquias, etc. Na verdade, o mercado é o agente de modulação dessas forças; ele deve reintegrá-las, domesticá-las, mas nunca poderia criá-las. Por outro lado, entretanto, nada pode sem elas. A produção desejante - aquilo que Negri e Hardt chamam trabalho vivo - é a base ontológica que, na máquina capitalista, é "tolerada" já que, sem ela, o sistema simplesmente emperraria, reproduzindo-se infinitamente num tempo morto. Sem o trabalho vivo não poderia haver exploração, comando ou controle.

Por isso, os autores fornecem outro modelo de explicação para a transição, ocorrida nos anos 60 e 70, do capitalismo fordista-keynesianista ao paradigma da acumulação flexível pós-moderno. É necessário descobrir, para além das mistificações do poder, a causa eficiente responsável pelo processo real que, mesmo traída pela reconfiguração do mercado, permanece como a causa real das transformações sociais. Ora, é no ciclo de lutas, que se intensificam no final dos anos 60, que encontramos os germes de uma revolução social generalizada que impôs transformações ao poder:

\footnotetext{
A história das formas capitalistas é sempre, necessariamente, uma história reativa. ... o capitalismo só se submete a transformações sistêmicas quando é obrigado ... Para captar o processo da perspectiva de seu elemento ativo, precisamos adotar o ponto de vista do outro lado ... o proletariado inventa, efetivamente, as formas sociais e produtivas que $o$ capital será obrigado a usar no futuro. (Negri \& Hardt, 2000, p.289)
}

Como exemplo dos ciclos de lutas que eclodiram nos anos 60 e 70, nomeados por Negri e Hardt na busca de conferir materialidade histórica aos eventos, 
podemos citar: as lutas antissocialistas nos países do leste europeu; as lutas anticoloniais; os movimentos pacifistas; a emergência do poder negro; o feminismo; as lutas pelos direitos dos homossexuais; as lutas anticapitalistas nos EUA e na Europa ocidental, assim como nos países "subdesenvolvidos"; os movimentos de recusa ao trabalho nas fábricas norte-americanas e italianas; os movimentos contra os hospícios e as prisões; o movimento hippie; o maio de 68 na França, etc. (Negri \& Hardt, 2000, pp. 281-300).

Essa série de acontecimentos é, então, causa da reação posterior, ou seja, da emergência de um novo capitalismo pós-moderno, que os autores denominam Imperial. Eles não são uma resposta à crise do capitalismo, não têm lugar no enfraquecimento da estrutura de comando disciplinar do fordismokeynesianismo. Pelo contrário, esses acontecimentos produziram esse enfraquecimento, produziram o desvio criativo de uma nova subjetividade, de novas maneiras de viver que ameaçam a ordem instituída. Maurizio Lazzarato, a respeito do maio francês, diz que "ele não foi consequência de uma crise, tampouco reação à crise. Pelo contrário, é a crise que ... deriva de uma mudança da ordem do sentido" (Lazzarato, 2004, p.14).

Se existiu captura, reconfiguração do poder, é porque houve expressão do desejo coletivo. $\mathrm{O}$ poder não cria: "A liberdade é a condição mesma da produtividade" (Negri \& Cocco, 2005, p. 69). Aqui reencontramos um dos aspectos ontológicos essenciais do pensamento de Bergson, retomado por Deleuze (1966/1999) na construção de sua filosofia: do nada, nada vem. Assumindo o ser como abertura e diferença, trata-se de não recair nas mistificações que postulam o nada, ou o negativo, como momento essencial na constituição do desejo coletivo. São as forças ativas, aquelas que Negri e Hardt chamam multitudinárias, que impõem mudanças ao poder, que forçaram o capital a buscar soluções de compromisso que permitissem um controle mais ou menos precário, um comando mais ou menos extenso, porém nunca absoluto, ou universal, da radicalidade do desejo coletivo.

\section{Notas}

1 A respeito da reintegração das reinvindicações, teóricas e práticas, de intelectuais e movimentos políticos dos anos 60 no que os autores chamam de "novo espirito do capitalismo", conferir Boltanki e Chiapello (2009). Podemos citar como exemplo a presença, nos manuais de neomanagement dos anos 80 , de algumas "ideias" retiradas à obra de Deleuze e Guattari. De fato, para os autores: "Embora o capitalismo não possa prescindir de uma orientação para o bem comum, da qual seja possível extrair motivos de engajamento, sua indiferença normativa não permite apenas que o espírito do capitalismo seja gerado apenas a parir de seus próprios recursos; assim, ele precisa de seus inimigos, daqueles que ele indaga, daqueles que se lhe opõe, para encontrar os pontos de apoio morais que lhe faltam e incorporar dispositivos de justiça que, sem isso, ele não teria nenhuma razão para considerar pertinentes ... ele encontrou em seus críticos mesmos os caminhos para a sobrevivência" (Boltanski \& Chiapello, 2009, p.62).

2 Brian Massumi define os agenciamentos sociais, em Deleuze e Guattari, como constituídos pela "junção de elementos separados através do acaso de encontros em persistentes, aparentemente estáveis, mais ou menos reproduzíveis conglomerados capazes de serem tomados por sua própria ilusão objetiva de identidade" (Massumi, 1992, p.47).

Deleuze, em "Controle e devir", pode afirmar que "no capitalismo, só uma coisa é universal, o mercado ... ele não é universalizante, homogeneizante, é uma fantástica fabricação de riqueza e miséria" (Deleuze, 1990, p. 213).

4 O Realé um conceito tomado por Zizek à obra do psicanalista Frances Jaques Lacan, que pensa o sujeito como estruturado por três instâncias fundamentais, o Real, o Simbólico e o Imaginário. O Real, neste esquema, desempenha justamente o papel do núcleo traumático, ou seja, daquilo que não pode ser significado, mas permanecesse como condição de qualquer significação: "O Real-como-impossível significa que ele acontece ... o Real só é impossível no sentido de que não se pode simbolizá-lo nem aceita-lo ... ele acontece, mas é traumático demais para ser assumido" (Zizek, 2006, pp. 203-204).

"No nível da forma, a economia capitalista tem âmbito universal. Portanto, o que me interessa é a dimensão estruturante global do que acontece no nível da economia capitalista. Não se trata apenas de um domínio entre outros" (Zizek, 2006, p.182).

6 Seria preciso proceder da mesma maneira que Spinoza constrói sua filosofia. Segundo Deleuze (1968), o filósofo Holandês impõe reinvenções radicais na história da filosofia utilizando-se de nomes tradicionais da escolástica medieval, como Deus, substância e atributo, e dando-lhes um sentindo radicalmente distinto, por vezes oposto, àquele consagrado pela tradição. Assim, o conceito de "diferença", quando utilizado num comercial de cartão de crédito, encontra-se tão próximo do conceito de diferença em Deleuze quanto, segundo o exemplo de Spinoza, a relação entre "cão, constelação celeste e o cão, animal que ladra, [que] em nada concordam além do nome" (Espinoza, 1677/2007, p. 41).

\section{Agradecimento}

À instituição de fomento: CNPq.

\section{Referências}

Boltanski, L. \& Chiapello, E. (2009). O novo espírito do capitalismo. São Paulo: Editora WMF Martins Fontes.

Deleuze, G. (1968). Spinoza et le probléme de l'expression. Paris: Les Edition de Minuit.

Deleuze, G. (1999). Bergsonismo. São Paulo: Editora 34. (Original publicado em 1966) 
Deleuze, G. (1990). Conversações. Rio de Janeiro: Editora 34.

Deleuze, G. \& Guattari, F. (1991). O que é a filosofia? Rio de Janeiro: Editora 34.

Deleuze, G. \& Guattari, F. (1995). Mil Platôs (Vol. 1). São Paulo: Editora 34. (Original publicado em 1980)

Deleuze, G. \& Guattari, F. (1997a). Mil Platôs (Vol. 4). São Paulo: Editora 34. (Original publicado em 1980)

Deleuze, G. \& Guattari, F. (1997b). Mil Platôs (Vol. 5). São Paulo: Editora 34. (Original publicado em 1980)

Deleuze, G. \& Guattari, F. (2010). O anti-Édipo. São Paulo: Editora 34. (Original publicado em 1972)

Espinosa, B. (2007). Ética. Belo Horizonte: Autentica Editora. (Original publicado em 1677)

Foucault, M. (1999). Vigiar e Punir. Rio de Janeiro: Editora Vozes. (Original publicado em 1975)

Guattari, F. (2005). Cartografias do desejo. Rio de Janeiro: Editora Vozes.

Harvey, D. (1989). A condição da pós-modernidade. São Paulo: Edições Loyola.

Harvey, D. (2006). Spaces of global capitalism. Verso: London.

Jameson, F. (1991). Ensayos sobre el pos modernismo. Buenos Aires: Ediciones Imago Mundi.

Jameson, F. (1997). Pós-modernismo. A lógica cultural do capitalismo tardio. São Paulo: Editora Ática.

Jameson, F. (2003). Modernidade Singular. Rio de Janeiro: Civilização Brasileira.

Lazzarato, M. (2004). As revoluções do capitalismo. Rio de Janeiro: Civilização Brasileira.

Massumi, B. (1992). A reader's guide to capitalism and schizophrenia. Massachusetts: The MIT Press.

Negri, A. \& Cocco, G. (2005). GloBAL: biopoder e lutas numa América Latina globalizada. Rio de Janeiro: Record.

Negri, A. \& Hardt, M. (2000). Império. Rio de Janeiro: Record.

Negri, A. \& Hardt, M. (2004). Multidão. Rio de Janeiro: Record.

Sibertin-Blanc, G. (2010). Deleuze et le anti-Oedipe. Paris: Presses Univercitaires de France.
Zizek, S. (1999). O superego pós-moderno. Acesso em 1 de maio, 2011, em

http://www.scribd.com/doc/19133295/Zizek-O-superegoposmoderno

Zizek, S. (2006). Arriscar o impossivel. São Paulo: Martins Fontes.

Zizek, S. (2008). A visão em paralaxe. São Paulo: Boitempo editorial.

Recebido em: 21/06/2011

Revisão em: 28/08/2012

Aceite em: 11/09/2012

Pedro Sobrino Laureano é professor assistente do Departamento de psicologia da Universidade Federal de São João del Rei (DPSCI-UFSJ). Doutorando em psicologia clínica pela PUC-RJ e membro da SPIDSociedade de psicanálise Iraci Doyle. Endereço: Av. Almirante Álvaro Alberto, 100/1001 São Conrado/RJ, Brasil. CEP 22610-070. E-mail: pedro@laureanopsi.com.br

Carlos Augusto Peixoto Junior é Psicanalista; Professor do Departamento de Psicologia e do Programa de Pósgraduação em Psicologia Cínica da PUC-Rio. E-mail: cpeixotojr@terra.com.br

\section{Como citar:}

Laureano, P. S. \& Peixoto Junior, C. A. (2014). Três pontos de vista sobre o capitalismo atual: um estudo a partir de Harvey, Jameson, Zizek, Deleuze e Negri. Psicologia \& Sociedade, 26(1), 2-11. 